\title{
The Relationship Between Organizational Safety Culture and Organization Safety Performance. The Mediating Role of Safety Management System
}

\author{
Otitolaiye VO', Abd Aziz FS², Munauwar $\mathrm{M}^{2}$, Omer F' \\ ${ }^{1}$ Department of Health Safety and Environmental Management, International College of Engineering and \\ Management, Seeb, Sultanate of Oman, ${ }^{2}$ School of Business Management College of Business, University Utara \\ Malayasia, Sintok, Kedah, Malaysia
}

\section{ABSTRACT}

Introduction: Safety performance is defined as efforts undertaken by organizations with the crucial aim of curtailing accidents and injuries to workers. It plays a crucial role in an organization aiming to achieve an anticipated outcome. A plethora of studies have found positive association between safety culture and safety performance of organizations. However, little is known on how the mechanism through which organizational safety culture exerts its influence on safety performance. Thus, this study investigates the indirect effect of safety management system in the relationship between organizational safety culture and safety performance.

Methods: This study employs the use of a 5-point Likert questionnaire to collect data from 134 respondents who are head of safety officers in F\&B industries located in Lagos, Nigeria. SmartPLS 2.0 was used for data analysis. Results: Results from path analysis revealed that safety culture and safety management system positively relate to safety performance. Furthermore, the mediation analysis indicated an indirect effect of safety management system in the relationship between safety culture and safety performance.

Conclusion: It is concluded that though safety culture has a significant positive relationship on safety performance, however its effect will be more if $F \& B$ organizations create and constantly implement a robust safety management system.

Key Words: F\&B Industries, Nigeria, Organizational Safety Culture, Safety Management systems, Safety Performance,

\section{Introduction}

he economic and sustainable development of any nation is greatly dependent on manufacturing industries, this can be seen by their contribution through production and exportation of goods and services. ${ }^{1}$ In

DOI: https://doi.org/10.3126/ijosh.v11i3.xxxx

Conflicts of interest: None

Supporting agencies: None

Date of submission: 06.07.2021

Date of acceptance: 03.09.2021

Date of publication: 30.09 .2021

\section{Corresponding Author}

Otitolaiye, Victor, O. MSc

Department of Health Safety and Environmental Management, International

College of Engineering and Management, Seeb, Sultanate of Oman.

Email: victorlaye@yahoo.com

ORCID ID: https://orcid.org/0000-0001-9110-999X
Nigeria, reports from National Bureau of Statistics in 2014 uncovered that manufacturing industries played a major role in the social and economic growth of the country. ${ }^{2}$ The report revealed that manufacturing industries contributed about $7 \%$ to Nigeria's GDP in 2013. Nonetheless, this contribution has deteriorated over the years. ${ }^{1}$ This deterioration was attributed to a range of factors among which workplace accident and injuries was given much prominence. ${ }^{3}$ This implies that safety is one growth propelling resources lacking at the disposal of Nigerian manufacturing industries and tends to weaken their performance and growth mechanisms. ${ }^{1}$

The Nigerian manufacturing industry is composed of nine sectors. ${ }^{4}$ Out of which the Food and Beverage

\section{(c) (1) (9)}

This journal is licensed under a Creative Commons AttributionNon Commercial 4.0 International License. 
(F\&B) industry has been the dominant in terms of size, population and in its contribution to the nations GDP over the years. ${ }^{2}$ In 2014 , its contribution stood at $52.74 \%$ of the total contribution of the manufacturing sector as compared to other sectors in the manufacturing industry. ${ }^{2}$ Moreover, this industry offered many employment opportunities for Nigerian people in 2014 with about 511,150 people engaged in this sector. ${ }^{4}$ Bearing in mind the number of employees in the F\&B industry, a significant amount of injuries and accidents take place in the industrial sites. ${ }^{4}$

According to data collected from National Institute of Safety Professional in 2014 it was disclosed that around 6205 occupational accidents occurred in F\&B industries representing $40 \%$ of the total accidents which occurred in the manufacturing sector. Likewise, Nigerian F\&B industries had reported huge sum of amount paid due to employee compensation from occupational accidents. ${ }^{4}$ Looking at the abovementioned problem it implies that safety performance in Nigerian F\&B industries is low.

Safety performance is defined as efforts undertaken by organizations with the crucial aim of curtailing accidents and injuries to workers. ${ }^{5}$ It plays a crucial role in an organization aiming to achieve an anticipated outcome..$^{6,7}$ Generally, organizations safety performance is lowered by occupational accidents. ${ }^{8}$ To reduce accidents in organizations, the concept of safety culture (SC) has frequently been studied. SC scholars have theorized that SC inclined organizations outperform organizations without safety culture. ${ }^{9-11}$ From the theoretical perspective, few empirical studies have been conducted on the relationship between SC and safety performance. ${ }^{12}$ Substantial amount of the extant literature shows that many of the researches were carried out in western countries ${ }^{12}$, little is known when leaving the western settings which has been studied in detail. ${ }^{13}$ As such there is a need to investigate the influence of organizational safety culture in Nigerian $F \& B$ industries with a view to relating it to their safety performance. Over the years the area of safety culture has received much emphasis from researchers, this is because the concept of safety culture is where safety actions and beliefs of organizations are positive resulting to a decreased chances of mishaps in an organization. ${ }^{8}$

Again, a lot of researchers that connect organizational SC to organizational safety performance such as
Mearns et al. ${ }^{14}$ have only focused on confirming that there is a link between organizational safety culture and organization safety performance through reduction in accidents, decreased material damages, employee motivation and reduced absenteeism, without addressing how and why this relationship exist. For instance, two important SC components like management commitment to safety has been reported to be positively related with organizational safety performance ${ }^{10}$ and employee involvement a prerequisite to better safety outcome in an organization ${ }^{16}$ without telling how and why. As a result of that the present study employs safety management system (SMS) as a mediator to address how the relationships exist. From the above-mentioned problem to the researcher's knowledge no study was found in the literature that provided an understanding of the mediating role of SMS on the relationship between an organizations SC and its safety performance. This is evidence that a gap exists for this study to re-examine, particularly within the context of F\&B manufacturing industries in Nigeria which are likely to differ from manufacturing industries in developed nations due to cultural differences.

\section{Organizational Safety Culture and Organizational Safety Performance}

A plethora of researchers have identified organization safety performance to have been significantly influenced by safety culture, for example: ${ }^{16,10} \mathrm{SC}$ is defined as a situation where commitment to safety by managers is rife within all spheres of the organization and are committed to reinforcing safety as a top organizational priority. ${ }^{10}$

Hajmohammad and Vachon emphasized that SC improves safety performance by reducing the severity and frequency of occupational incidents through established SC factors like management commitment and employee involvement. ${ }^{10}$ Their findings after collecting data from 251 Plants in Canada gave empirical support to the aforementioned. The same is reported among 455 Spanish firms by Fernandez-Muniz et al. ${ }^{17}$ Organizations with improved safety culture tends to display a high level of safety performance thus a resultant decrease in mishaps within the organizations. Thus, this study examines the role of organizational safety culture on Organizational safety performance in F\&B industries. Hence, we posit that

Hypothesis 1: Safety culture will be positively related with organizational safety performance. 


\section{Safety Management System and Safety Performance}

Safety management system are tools used by management in organization for managing safety. ${ }^{16}$ They include set of policies, practices, roles, procedures, and functions that relates to safety. ${ }^{14}$ Also, safety management system can be referred to as mechanisms incorporated in organizations, planning to curb hazards which affect safety and health of workers. ${ }^{18,19}$ In the same vein, safety management system allows a firm to act in accordance with current legislations ${ }^{19}$ and plays a crucial role in the implementation of occupational safety and health at workplace, and for preventing the organizational accidents. ${ }^{17,18}$

Earlier studies that associated the concept of safety management system with safety performance and other safety related outcomes have found results that supports SMS to have elicited performance outcomes. ${ }^{16,20,17}$ For instance, Wachter and Yorio found significant negative relationship between safety management system and accident rates. ${ }^{21}$ Naveh, KatzNavon and Stern carried out a study among hospital organizations to determine how patient safety had been improved by SMS implementation, result indicated that higher scores of patient safety was because of safety management system implementation. ${ }^{22}$ These studies suggest a strong association between SMS and SP. ${ }^{17}$ Organizations that implement an SMS would more likely have superior safety performance. ${ }^{23}$ Similarly, Bottani et al. confirmed that out of 116 organizations studied, organizations that implemented safety management system showed higher score of safety performance than organizations without SM. ${ }^{24}$ Thus, we propose that SMS will play a vital role in reducing accidents in organizations thus achieving safety performance. Therefore, we posit that

Hypothesis 2: Safety management system will be positively related with organizational safety performance.

\section{Mediating Role of Safety management system}

The urge to create new ideas is generally spurred on by a culture which encourages shared vision of action. ${ }^{25}$ Safety culture can inspire an organization to initiate a safety management system, which may in turn improve the safety performance of the organization ${ }^{26}$. For example, Wu et al. had identified that safety culture establishment is a key requisite in developing an SMS in an organization which consequently result to an increase in safety performance ${ }^{7}$. Empirically, Hajmohammad and Vachon found safety practices and procedures that are embedded in a safety management system to have mediated the relationship between safety culture and safety performance at the organization level of analysis. ${ }^{10}$ Similarly, Fernandez-Muniz et al. found an SMS to have mediated the relationship between a key SC component, management commitment to safety and safety performance among Spanish firms. ${ }^{20}$ More so, McFadden et al. proposed a chain for safety outcome achievement by safety culture in health care organizations through safety initiative implementation, they emphasized that other safety management practices can serve as a mechanism between safety culture and outcome of safety performance achievement. ${ }^{11}$ In view of this and based on the earlier argument, the following hypotheses will be proposed:

Hypothesis 3: Safety management system mediates the relationship between safety culture and safety performance.

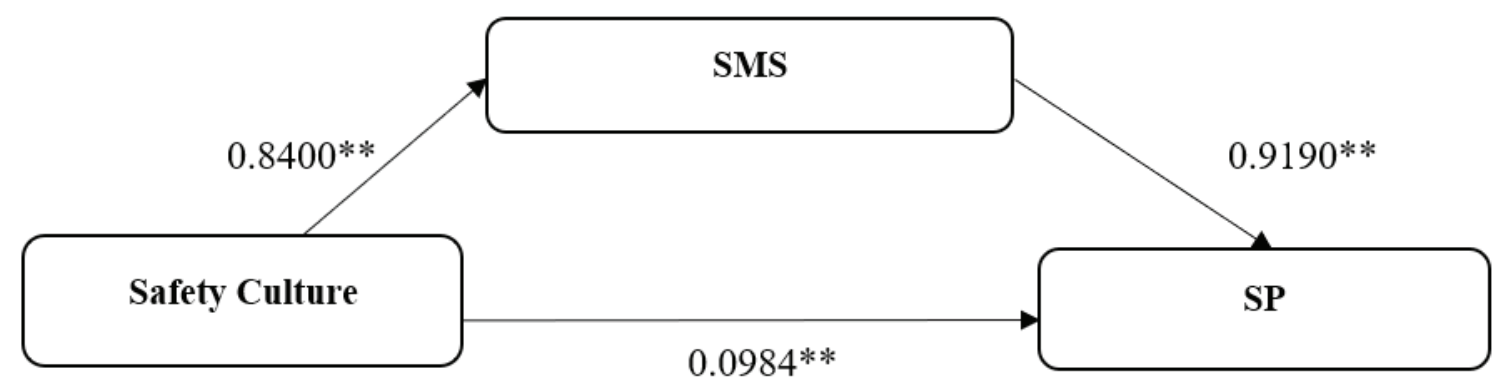

Figure 1: Theoretical Model for the Research 


\section{Methods}

This study utilizes a simple random sampling technique to draw out participants from the accessible population. The population of this study include all F\&B industries in Lagos state Nigeria. This study was conducted using questionnaires administered by hand to Head of safety officers (HSO's) in F\&B Industries in Lagos state Nigeria. HSO's were chosen because they are expected to have insight about specific practices and procedures that are been carried out in their organizations. Thus, the level of analysis was organizational based, which means that the data collected from each Head of Safety Officers (HSO's) represent their respective organization. A total number of 350 F\&B industries were obtained from Manufacturers Association of Nigeria directory (MAN, 2015). The sample size of this study was estimated using G-power analysis since the sample frame might be indeterminate. Upon analysis from $G^{*}$ Power, using the number of predictors which are safety culture and safety management system from the study framework, the sample size for the study was 107. However, to achieve an appreciable level of response rate, Bartlett, Kotrilik and Higgins suggested that the size of the population be added by at least $50 \%$ of the required sample. ${ }^{27}$ Based on this argument, a sample size of 71 was added to the required sample frame of 107 which equaled 178 .
Before responding to the questionnaires, we secured their consent to participate in the study. Ethical approval for this study was gotten from the Office of the Directorate of Occupational Safety and Health Department Ministry of Labor and Productivity FCT Abuja. Out of the 134 responses from HSO who took part in the survey, 126 results were found valid. The valid response rate was $71 \%$. The distribution of respondents by status showed that there were $11(8.7 \%)$ middle rank staff and 115 (91.3\%) were of senior level.

Measures: Safety culture was measured using seven items adopted from a safety climate survey by Sexton et al. ${ }^{28}$ Similar to Hajmohammad and Vachon and McFadden et al. approaches, this study incorporated only seven out of the 19 original items that measured safety culture at the organizational level and were closely linked with safety culture definition. ${ }^{10,11}$ All items were measured using a five-point Likert scale that ranged from 1 (strongly disagree) to 5 (strongly agree). Studies like Hajmohammad and Vachon and McFadden et al. reported reliabilities of 0.89 and 0.911 respectively which is within acceptable limits stated by Nunnaly. ${ }^{10,11,29}$ The Cronbach Alpha for safety culture in the present study was 0.854

Safety Management System was measured as a second order construct using six dimensions in their first order adopted from Fernandez-Muniz et al. ${ }^{19}$

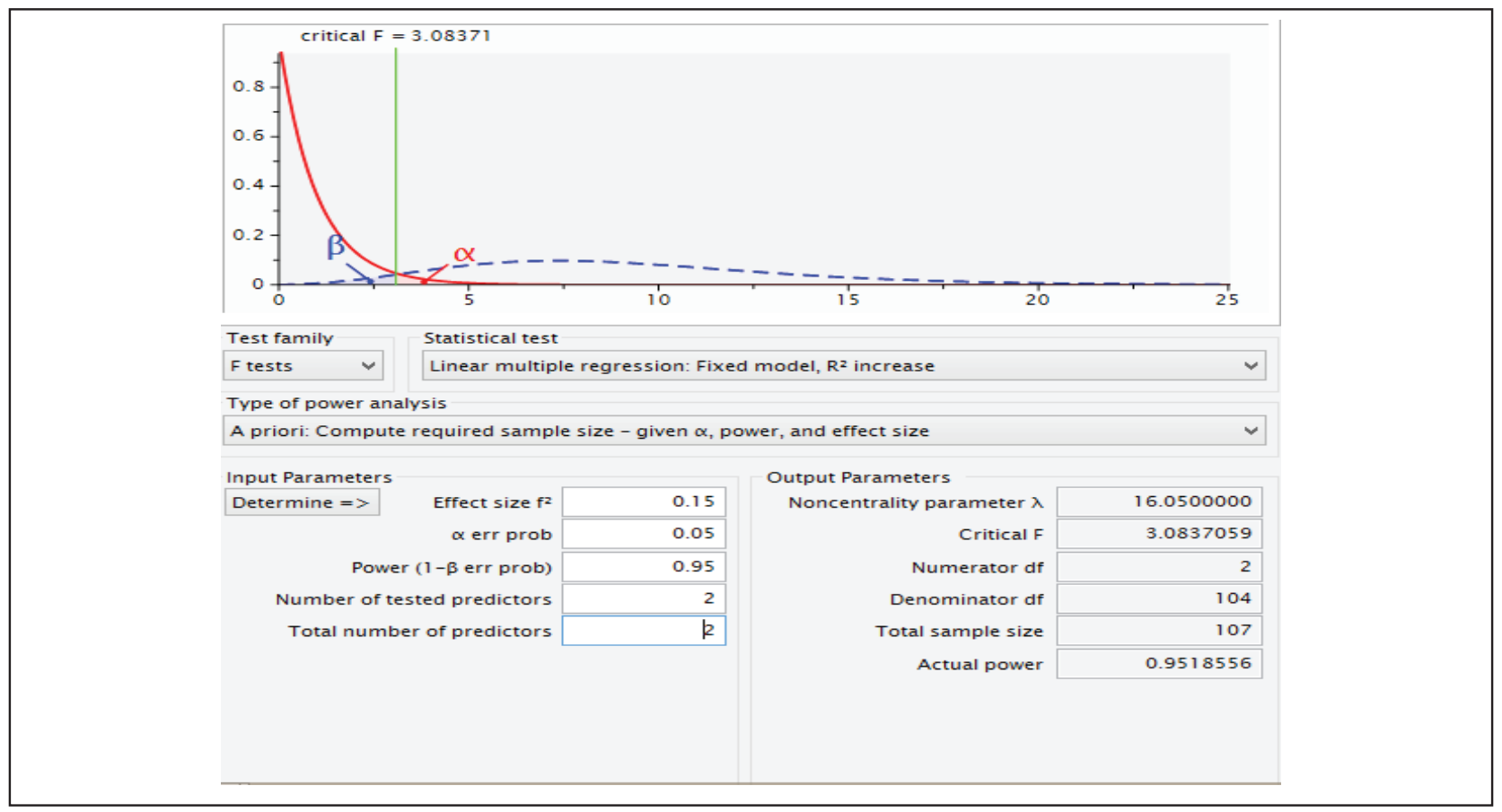

Figure 2: Sample size determination using G-power analysis 
These dimensions have 29 items which were reframed to suit the study context. Items covered a wide range of safety management system dimensions which includes planning, policy, training in safety, communication, incentives, control. All dimensions were reported to have composite reliability ranging from 0.87-0.96 which is recommended by Nunnaly. ${ }^{29}$ All these items were measured using a 5-point likert scale and were coded on a scale of 1 (strongly disagree) to 5 (strongly agree). In the present study all safety management system dimensions which are planning, policy, training in safety, communication, incentives, control had a Cronbach alpha of $0.794,0.823,0.866,0.792,0.851$ and 0.862 , respectively.

To measure safety performance this study adopted items from Fernandez-Muniz et al. ${ }^{19}$ Safety performance was measured subjectively by 4 items using a 5 point likert scale which range from 1 (extremely dissatisfied) to 5 (extremely satisfied). Studies like FernandezMuniz et al. ${ }^{19}$ reported reliability of 0.746 which is within acceptable limits as suggested by Nunnally. ${ }^{29}$ The
Cronbach Alpha for safety performance in the present study was 0.862

\section{Results}

This section presents, the structural model, and the result of the hypotheses testing for the direct effects. To achieve this, PLS path modelling multiple regression technique was used to test the direct interactions.

By using the above stated method, path coefficients were determined using t-statistics. A one-tailed distribution was used to assess the significance level of the t-value as opined by Chin. ${ }^{30}$ According to Sharma, for t-values to be significant in a one tailed statistical test, it must be greater or equal to 2.326 at $1 \%$ significance level, it must be greater or equal to 1.645 at $5 \%$ significance level and it must be greater or equal to 1.282 at $10 \%$ significance level. ${ }^{31}$ Any t-values that is less than the earlier stated t-values are considered not significant. The direct effects are stated in Table1 below:

Table 1: Paths Coefficients

\begin{tabular}{|c|c|c|c|c|c|}
\hline Hypothesis & Relationship & Beta values & Std Error & T Statistics & Probability value \\
\hline $\mathrm{H} 1$ & $\begin{array}{l}\text { Safety culture -> Safety } \\
\text { performance }\end{array}$ & 0.0984 & 0.0686 & 1.4302 & 0.0651 \\
\hline $\mathrm{H} 2$ & $\begin{array}{l}\text { Safety culture -> Safety } \\
\text { Management system }\end{array}$ & 0.8400 & 0.0335 & 25.095 & 0.0000 \\
\hline $\mathrm{H} 3$ & $\begin{array}{l}\text { Safety Management system } \\
\text {-> Safety performance }\end{array}$ & 0.9190 & 0.0868 & 10.5788 & 0.0000 \\
\hline
\end{tabular}

$\mathrm{P}<0.01$

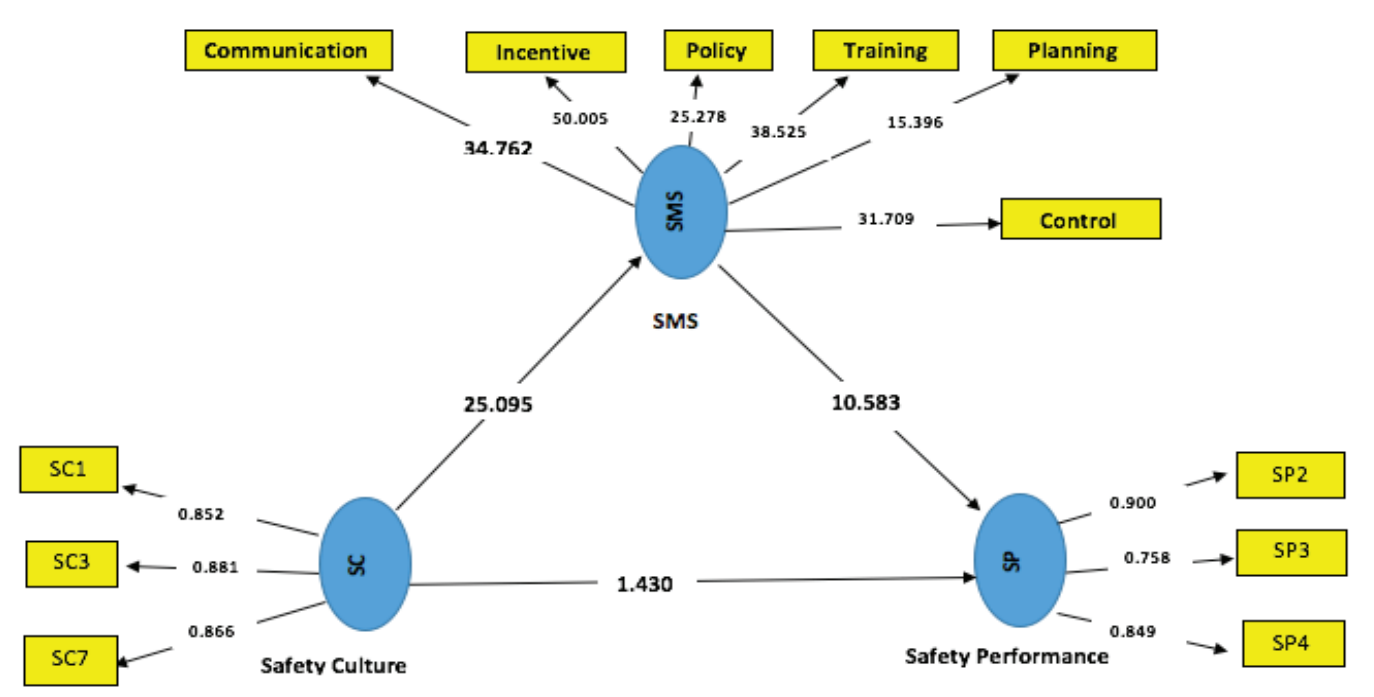

Figure 3: Result of the Path Analysis 
Table 1. shows the results of the path coefficient (Betavalues), standard error, t-values, and decision taken for the study. In summary, the result of the hypotheses testing of the direct relationship as shown in Table 1. showed that all accepted hypotheses had a t-value above 1.282 (10\% significance level for one-tail test). The significant relationship for the direct hypothesis includes $\mathbf{H 1}(\beta=0.0984 ; t=1.4302 ; p>.05), \mathbf{H} 2(\beta=$ 0.8400; $t=25.095 ; p<.1), \quad H 3(\beta=0.9190 ; t=10.5788$; $p<.1)$. The result of the path analysis is presented in Figure 2. The latent variable scores from the measurement model for all first order construct was determined and used to determine the structural model to reduce the complexity of the model, then path analysis was determined using bootstrapping. The next section presents the fourth hypothesis $(\mathbf{H} 4)$ of the study.

\section{Mediating Effect Hypothesis}

To achieve the fourth hypothesis ( $\mathbf{H 4}$ ), a mediating test as mentioned by Ramayah et al. ${ }^{32}$ was carried out to see if the influence of the independent variable is extended to the dependent variable by the mediating variable. This study utilised resampling mediation technique i.e., bootstrapping and path coefficients by Hayes and Hayes. ${ }^{33}$ This method is firstly done by finding out the t-values and path coefficients using the independent variable and the dependent variable with no mediator and secondly utilizing the mediator as well as the standard errors. In the present study, two different links were obtained which are "a" signifying the path of the independent variable to the mediating variable (X-M), "b" which signifies the second path from the mediating variable to the dependent variable (M-Y). Calculation of the modified standard error for the product of $a * b$ was done and the critical ratio was also determined which was employed to estimate t-values linked with the product of $a * b$. This study assessed the influence of the mediating variable with SmartPLS $2.0 \mathrm{M} 3$ by utilizing the bootstrapping and the model displayed the $t$-values. The $t$ values are calculated by using the formula below as provided by Hayes and Preacher. ${ }^{33}$

$T_{a b} T_{a b}=\frac{a * b}{S_{a b}} \ldots \ldots \ldots \ldots . . .$. eq. 1

Where:

$\mathrm{a}=$ path loading value of the relationship between the independent variable and the mediator.

$b=$ path loading value of the relationship between the mediator and the dependent variable.

$S a b=$ standard deviation of $a$ and $b$ above.
Table 2 presents the result of the mediating effect of safety management system on the relationship between safety culture and safety performance. If $t$-value of $a * b$ is $>1.96$ mediation is said to exist otherwise not.

Table 2: Test of mediation of SMS

\begin{tabular}{cc}
\hline & Safety culture (SC) \\
\hline $\mathrm{a}^{*} \mathrm{~b}$ & 0.649 \\
$\mathrm{Sab}$ & 0.070 \\
$\mathrm{~T}$ & 9.294 \\
\hline
\end{tabular}

Note: Significance of $t$ values at $1 \%$. Where $\mathrm{Sab}=$ Standard deviation of $a$ and $b, t=t$ value for mediation, $a^{*} b=$ product of independent variable path to the mediator and mediating variable path to the dependent variable.

The table 2 shows the significant $t$ value of the mediating effect of SMS on the relationship between safety culture and safety performance. Hence hypothesis $\mathbf{H 4}$ is supported. The result shows the t value of 9.294 was significant at $p$ value of $1 \%$.

\section{Discussion}

This study investigated the link between SC and organizational safety performance, with the indirect influence of safety management system on the relationship between $S C$ and safety performance in F\&B industries in Lagos Nigeria.

As hypothesized, our findings revealed that safety culture was positively related to safety performance. The findings give credence to the fact that organizations with a strong safety culture tend to outperform organizations with negative safety culture. ${ }^{17,14}$ Organization safety culture refers to the value an organization place on safety. ${ }^{11}$ The result puts forward that firms with a positive safety culture tend to have better safety outcome because upperlevel management care about wellbeing and safety of employees, employees in such firms are empowered, involved actively, and partake in activities that are safety related which are beneficial to the organization. Safety culture provides ways to the essential design and operating techniques of an organization and helps organizations to avoid accidents thus improving safety performance. ${ }^{17}$

Also, Carder and Ragan ${ }^{34}$ stated that firm's safety performance can be improved when the firm's demonstration of its management commitment to safety allows employees to be involved in safety related activities which is a proxy for the organization's safety culture. Similarly, Vecchio-Sadus and Griffith 
indicated that the essential ingredient in accomplishing a positive safety culture in an organization is when firm's management are committed towards safety of their employees and get employees involved in problem solving and decision-making process. ${ }^{15}$ The benefit does not only reduce injury rates, but also offers financial and social rewards to such organizations. One possible reason why safety culture was found positively related to safety performance was because F\&B industries in Nigeria had not implemented a positive safety culture hence, this might likely influence firm's outcome of safety as such it translates in their safety performance.

The present line of result is consistent with previous studies by done at the organizational level of analysis ${ }^{19,10,11}$. In addition, the findings of this study are in line with the resource-based view theory as postulated by Barney. ${ }^{35}$ The resource-based view holds that successful and efficient application of resources (rare inimitable) will facilitate organizations achievement of competitive advantage. ${ }^{35}$ Organizational culture has been studied as rare and inimitable resources owned by organization which enhances organizations competitive advantage which in turn shapes a firm performance. Taking a leaf from this it could be said that the safety culture gives organizations superior advantage consequently improving their performance. In essence it implies that firms that implement rare inimitable nonsubstantial resources like its safety culture can present competitive advantage and high performance for an organization in current competitive market. ${ }^{35}$ As such firms should instil a culture of safety which offers a firm a means to achieve competitive advantage and consequently superior safety performance.

Furthermore, the current study hypothesized that safety management system is positively related to safety performance. This hypothesis was supported. In this study, safety management system refers to sets of persons, policies, resources, procedures, and practices which act together in an organized manner to ease damage and losses caused in the process and place of work. ${ }^{18}$ It offers an organized contrivance for firms to constantly enhance safety and sets the organizational policies, procedures, structure, and processes, which offers the organization the ability to guarantee safe operations. ${ }^{17}$

The findings obtained in the current study further validate earlier works that attempted to explore the relationship between safety management system and safety performance. Some of the studies include Fernandez-Muniz et al. and Bottani et al. In addition, Fan and Lo also found safety management system implementation to had effectively enhanced firms' financial performance. ${ }^{20,24,36}$ One justification for the positive relationship could be found in Robotham who emphasized that the presence of managers who show commitment to safety within an organization is a prerequisite for the success of an SMS, as at the time this study was conducted, the respondents which were Head of safety officers had adequate educational experience which is reflected in their level of commitment towards safety of their employees. ${ }^{37}$

The implication of this finding reveals that deployment of safety management system in firms enables the achievement of the firms' safety objectives like reduction material damages, personal injuries, increase in employee satisfaction as well as their motivation. As such, the more firms are committed to safety management system implementation, the better their achievement of safety performance. Knowing the importance of this correlation, many organizations today now commit lots of resources towards safety management system implementation to encourage achievement of safety goals thus minimising cost incurred on safety.

Finally, this study hypothesised that SMS would mediate the relationship between safety culture and safety performance. The hypothesis was supported. This result indicates that firms with a positive safety culture are likely to introduce a safety management system which will result to a desired performance. This means that though safety culture are resources to improve organization's safety performance, however the impact on safety performance will be greater when Nigerian F\&B industries develop and implement a strong SMS. It also implies that relevant and strong SMS can transfer the impact of safety culture to safety performance thereby improving safety performance. Put differently, it means that safety culture passes through SMS to affect safety performance. The result is supported by $\mathrm{Wu}$ et al. ${ }^{7}$ who reiterated that safety culture improvement is essential to the development of a safety management system which is an ingredient for safety performance improvement. In addition, Fernandez-Muniz et al. ${ }^{20}$ also reiterated safety management system mediated management value for safety and safety performance. Furthermore, Hajmohammad and Vacchon indicated the role of safety practice in mediating the relationship 
between safety culture and safety performance. ${ }^{10}$ This result as well confirms the patient safety chain model put forward by McFadden et al. for health care industry, as it provides empirical evidence for the safety cultureinitiative-outcome model in a food and beverage manufacturing context. ${ }^{11}$ Knowing the importance of safety management system in an organization, it is necessary for firms to adopt a positive safety culture which helps to develop the safety management system and thus a better safety performance, as such organizations should strengthen their safety culture in all ramifications.

This study has key managerial implication to manufacturing leaders in Nigeria because improving safety has turned out to be a national priority. Therefore, this study provides empirical support that safety culture is tied to better safety outcome, this suggests that when organizations especially F\&B industries in Nigeria desire to make improvements in safety, there is a need to base their emphasis on improving a safety culture. This study also provides support that improved care given to employees by management is beneficial to organizational goals, this can assist to enhance morale of workers thus enabling them to have self-assurance in the management of the organization.

Maintaining a positive safety culture is vital to an organizations success since it plays a crucial role in the development of a safety management system which helps organizations to reduce the level of safety hazards and occurrences, thus reducing related financial costs incurred. Such organizations avoid much medical bills and allowances for hospitalized employees or compensations paid to family members of employees involved in occupational accidents or hazards. It should be noted that expenses incurred by firms because of such accidents subject's firms to an undesirable profitability and economic outcome thus it deters their competitive advantage in the global market.

Additionally, it should also be noted that previous studies on occupational safety and health on safety culture were done in Western and Asian countries, however this study was done in a non-western and non-Asian setting hence it adds to the body of

\section{References}

1. Sangosanya AO. Firms' growth dynamics in Nigeria's manufacturing industry: A panel analysis. Journal of Applied Econometric Review. 2011;1(1):1-8. knowledge. Findings from this study comprise the first piece of empirical research on the mediating role of SMS on the relationship between SC and safety performance in Nigeria, as such other studies can also consider incorporating SMS as mediators in their study as findings from this study has proven its workability.

One limitation of this study is that this study was done using a cross-sectional method in which data were collected at a particular point in time. However, some studies stated the benefits of sustainable manufacturing practices can be achieved in a long term rather than short term. Therefore, studying the phenomena of safety performance in manufacturing like $F \& B$ industry in more than one point in time (longitudinal study) is recommended. It should be borne in mind that this study was conducted in Lagos which represents one out of the 36 states of Nigeria as such findings from this study cannot be generalized to all F\&B industries in other states and geo-political zones of the country.

\section{Conclusion}

This study has empirically shown the established connection and relationships among the variables, and it has tested both the direct and the mediating relationships in order to provide answers to the said research hypothesis of the study. Upon the validation of the research instrument used in this study, data were collected from 126 safety officers of F\&B manufacturing firms in Nigeria. The evaluation of both the measurement and the structural model was done and evidence were found to support the result of the analysis. All hypothesis of the study was supported thus achieving the objective of the study. More significantly the study fills the gap by finding out that safety culture/ safety performance relationship is explained by the implementation of a firm safety management system, additionally it reveals that safety performance of firms is tied to successful deployment and development of a successful safety culture as well as a safety management system. Lastly firms who have a positive safety culture in turn implement an adequate safety management system, thus making this study special in its own rating and a contribution to the body of knowledge

2. National Bureau of Statistics. Nigerian manufacturing sector summary report. 2012. Abuja Federal Republic of Nigeria. Available from: www.nigerianstat.gov.ng. [Accessed 14th October 2014]. 
3. Omoyajowo OO. A Risk Management Approach for Nigeria Manufacturing Industries. International Journal of Industrial and Manufacturing Engineering. 2016.10(8):1410-3. doi.org/10.5281/zenodo. 1125741

4. National Bureau of Statistics. Nigerian Gross Domestic Product Report. National Bureau of Statistics. Report number: Q2, 2020. Available from: www.nigerianstat. gov.ng. [Accessed 14th October 2014].

5. Otitolaiye VO, Aziz FS, Mustafa M, Nyakuma BB. Fundamental Concepts, Dimensions, Measures, and Drivers of Safety Performance in Organizations: A Concise Review. Petroleum and Coal. 2021.63(2): 346-55

6. Khan N, Ahmad I, llyas M. Impact of ethical leadership on organizational safety performance: the mediating role of safety culture and safety consciousness. Ethics \& Behavior. 2018.28(8):628-43. Available from : https:// doi.org/10.1080/10508422.2018.1427097

7. Wu TC, Lin $\mathrm{CH}$, Shiau SY. Predicting safety culture: The roles of employer, operations manager and safety professional. Journal of safety research. 2010.41(5):423-33

8. Laal F, Pouyakian M, Madvari RF, Khoshakhlagh AH, Halvani $\mathrm{GH}$. Investigating the impact of establishing integrated management systems on accidents and safety performance indices: A case study. Safety and health at work. 2019.10(1):54-60.

9. Boughaba A, Hassane C, Roukia O. Safety culture assessment in petrochemical industry: a comparative study of two Algerian plants. Safety and health at work. 2014.5(2):60-5.

10. Hajmohammad S, Vachon S. Safety culture: A catalyst for sustainable development. Journal of business ethics. 2014.123(2):263-81.

11. McFadden KL, Henagan SC, Gowen III CR. The patient safety chain: Transformational leadership's effect on patient safety culture, initiatives, and outcomes. Journal of Operations Management. 2009. 27(5):390404.

12. Guldenmund FW. The nature of safety culture: a review of theory and research. Safety science. 2000.34(13):215-57.

13. Hudson P. Implementing a safety culture in a major multi-national. Safety science. 2007. 1;45(6):697-722.

14. Mearns K, Whitaker SM, Flin R. Safety climate, safety management practice and safety performance in offshore environments. Safety science. 2003.41(8):64180.

15. Vecchio-Sadus AM, Griffiths S. Marketing strategies for enhancing safety culture. Safety Science. 2004.42(7):601-19.

16. Fernández-Muñiz B, Montes-Peón JM, VázquezOrdás CJ. Safety leadership, risk management and safety performance in Spanish firms. Safety science. 2014.70:295-307.
17. Fernández-Muñiz B, Montes-Peón JM, VázquezOrdás CJ. Relation between occupational safety management and firm performance. Safety science. 2009.1;47(7):980-91.

18. Labodová A. Implementing integrated management systems using a risk analysis-based approach. Journal of cleaner production. 2004.1;12(6):571-80.

19. Fernández-Muñiz B, Montes-Peon JM, Vazquez-Ordas CJ. Safety management system: Development and validation of a multidimensional scale. Journal of Loss Prevention in the process Industries. 2007.20(1):5268.

20. Fernández-Muñiz B, Montes-Peón JM, Vázquez-Ordás CJ. Safety culture: Analysis of the causal relationships between its key dimensions. Journal of safety research. 2007. 1;38(6):627-41.

21. Wachter JK, Yorio PL. A system of safety management practices and worker engagement for reducing and preventing accidents: An empirical and theoretical investigation. Accident Analysis \& Prevention. 2014. 68:117-30.

22. Naveh E, Katz-Navon T, Stern Z. The effect of safety management systems on continuous improvement of patient safety: The moderating role of safety climate and autonomy. Quality Management Journal. 2011.18(1):54-67.

23. Hong CC, Ramayah $T$, Subramaniam C. The relationship between critical success factors, internal control and safety performance in the Malaysian manufacturing sector. Safety science. 2018. 104:17988.

24. Bottani E, Monica L, Vignali G. Safety management systems: Performance differences between adopters and non-adopters. Safety science. 2009.47(2):155-62.

25. Hamel G, Prahalad CK. Strategic intent. Harvard business review. 2005;83(7):148-61.

26. Kim NK, Rahim NF, Iranmanesh M, Foroughi B. The role of the safety climate in the successful implementation of safety management systems. Safety science. 2019. 118:48-56.

27. Bartlet JE. II, Kotrlik JW, Higgins CC. Organizational research: Determining appropriate sample size in survey research. Info Tech, Learning, and Perf J .2001.19(1):43-50.

28. Sexton JB, Helmreich RL, Neilands TB, et al. The Safety Attitudes Questionnaire: psychometric properties, benchmarking data, and emerging research. BMC Health Serv Res. 2006;6:44. Available from : https:// www.ncbi.nlm.nih.gov/pmc/articles/PMC1481614/

29. Nunnally JC. An overview of psychological measurement. Clinical diagnosis of mental disorders. 1978:97-146

30. Chin WW. The partial least squares approach to structural equation modeling. Modern methods for business research. 1998.295(2):295-336. 
31. Sharma, P., Galit Shmueli, M. Sarstedt, N. Danks and Soumya Ray. "Prediction-Oriented Model Selection in Partial Least Squares Path Modeling." Decis. Sci. 52 (2021): 567-607.

32. Ramayah T, Samat N, Lo MC. Market orientation, service quality and organizational performance in service organizations in Malaysia. Asia-Pacific Journal of Business Administration. 2011.3. 8-27.

33. Hayes AF. Beyond Baron and Kenny: Statistical mediation analysis in the new millennium. Communication monographs. 2009 Dec 1;76(4):40820.

34. Carder B, Ragan PW. A survey-based system for safety measurement and improvement. Journal of safety research. 2003.34(2):157-65.
35. Barney J. Firm resources and sustained competitive advantage. Journal of management. 1991.17(1):99120.

36. Fan D, Lo CK. A tough pill to swallow. The impact of voluntary occupational health and safety management system on firms' financial performance in fashion and textiles industries. Journal of Fashion Marketing and Management: An International Journal .2012.16(2):128-40.

37. Robotham FG. The 15 Most Important Components of an Effective Safety Management System. 2012. Available from http://www.ohschange.com.au/ articles/The_15_Most_Important_Components_of_ an_Effective_Safety_Management_System/The_15_ Most_Important_Components_of_an_Effective_ Safety_Management_System.html[Accessed 14th October 2020]. 